assimilation of stable chords (accords) used in the modern music. Some general methodological guidelines of class work choir score reading towards the formation of hearing representations about the regular consonances as an element of the harmonic language are established.

Keywords: modern harmony, choral music of the twentieth century, harmonic hearing, chord, and choir score reading.

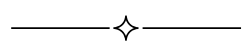

УДК 781.68/786.2

\title{
A. Сапсович
}

\section{ФОРТЕПИАННАЯ СОНАТА С. СЛОНИМСКОГО: ОСОБЕННОСТИ ФОРМООБРАЗОВАНИЯ И ИСПОЛНИТЕЛЬСКОЙ ИНТЕРПРЕТАЦИИ}

В статье рассматриваются формообразующие принципы Фортепианной сонаты С. Слонимского. Выясняется, что в сочинении претворились черты четырехчастного симфонического цикла, где I часть совмещает композиционные функиии (В. Бобровский) сонатного аллегро и медленной части, а II часть - скерио и быстрого финала. В анализе исполнительской интерпретации специальное внимание уделено проблемам фразировки, а также вопросам правомерности частично редуцированного (с купюрами) исполнения.

Ключевые слова: драматургия, формообразование, фразировка, композиционные функции, принцип мотетности.

Датированная 1962 годом Фортепианная соната считается «своеобразным манифестом» С. Слонимского, его «декларацией», в которой излагаются основные идеи творчества, образно-тематический строй, а вместе с ними - главенствующие принципы драматургии, музыкального языка композитора [2, с. 429]. Вместе с тем формообразующий аспект и проблемы исполнительской интерпретации этого сочинения на сегодняшний день являются малоизученными.

По мнению И. Рогалева, структура одночастной Фортепианной сонаты С. Слонимского образована синтезом свободно трактованной формы сонатного аллегро, трехчастного цикла (ПП идентична жанровой части) и принципа мотетности. Известно также мнение Е. Ручьевской (которое упоминает и Рогалев), что форма данного сочинения может быть определена как развитая двухчастная [2, с. 429].

(C) Сапсович А., 2015 
Попытаемся подойти к проблеме формообразования в этом сочинения как можно более основательно, подкрепив наши размышления в этом направлении соответствующим анализом.

Трижды повторенное на ррр ля контроктавы имитирует приглушенное звучание колокола. Из этих первых трех звуков «вырастает» основная тема Сонаты (первой ГП). Размеренный темп, низкий регистр, одноголосное «скупое» изложение, ходы на широкие интервалы, одинадцатиновый звукоряд придают ей сумрачный колорит и угрюмое спокойствие. Неспешно разворачивается «гамлетовская» мысль о тяжести бытия...

И. Рогалев называет эту тему Cantus firmus всего произведения, обнаружив ее замечательное специфически ладовое свойство соединения звукорядов двух ладов с общей терцией - Си мажора и до минора. Суммарная тоника этих ладов становится «зоной вводнотоновости» всего ладового каркаса сочинения, а если учесть важность ладового сопряжения в формообразовании у Слонимского, то и для драматургии Сонаты в целом.

Вторая тема представляет собой мелодическое «вращение» в малотерцовом диапазоне. Ее народно-песенный характер подтверждает малообъемная диатоническая основа. Этот мотив - своеобразный ладовый «мост» между первой атональной и третьей тональной темами.

Третья тема главной партии (составляющее ее второе мотетное звено) - былинного характера, образует еще один «модус спокойствия» в Сонате, на этот раз - эпически-остраненного, что подтверждает авторская ремарка quasi coro. От предыдущего тематизма эту тему отличают «шаговая» мерность половинных и четвертных длительностей, квартово-квинтовые начальные ходы, подчеркнуто кантиленное звучание, которого требуют тщательно продуманные лиги. Необычная акустическая особенность этой неприкрыто тональной, до минорной темы - входящий с нею в определенный «резонанс» «зонный» тонический бас «си» (впрочем, диссонантность звучания частично снимается низким регистровым звучанием последнего).

Далее следуют образующие единую фразировочную волну четвертая тема главной партии, гармонизованный и «ритмизованный» вариант второй темы Сонаты (в дальнейшем, особенно во II части цикла, она приобретет самостоятельное значение), совместное проведение первых двух тем (с 21-го такта) и словно вырастающая из этого синтеза, новая, нисходящая, секундовая, подчеркнутая форшлагами, интонация плача. 
Четвертая, относящаяся к сфере главной партии, тема-раскачка, начинающаяся с нового ладотонального устоя - «фа», с дважды повторяющимся «преодолением» - занятием все большей интервальной вершины - сначала терции, затем сексты, также интонационно явно связана с предыдущим музыкальным материалом. Кроме интонационного и ладового обновления тематизма, данная тема открывает и новую артикуляционную грань в исполнении на фортепиано, что обозначается авторским portamento.

Эмотивное беспокойство, характеризующее начало выше обозначенной фразировочной волны (соответствующие характеру нового тематизма) сменяется смысловой и эмоциональной «схемой» нахождения и «педалирования» одной и той же навязчивой мысли (многократное, «вдалбливающее», маркатированное повторение одного звука (ля бемоль, затем $c и$ ) с «разрешением» в различные интервалы (б 2, ч 4, м 2), с постепенным восхождением к вершине; за последней следует динамический спад и появление интонации плача с характерными для ряда народных песен «курлыканиями», обозначенными в нотном тексте форшлагами.

Зона побочной партии представлена двумя темами песенно-лирического характера. Далее гармонизуется ранее монодийная четвертая тема.

Такты 85-107 собирают «в тугой узел» весь тематизм. Из последнего логично «вырастает» контрапунктическое совмещение материала в тактах 108-139 (с больш им динамическим усилением, широким диапазоном, октавным дублированием и аккордами в низком регистре).

Последующий эпизод - ff, marcato cantabile - продолжение кульминации и ее вершина - И. Рогалев трактует как «местную репризу-коду», подытоживающие процессы, происходящие на уровне тематизма и возвращающие много раз нарушавшуюся до того ладовую бинарность «си» - «до» [2, с. 435].

В последних тактах звучание былинной (третьей ГП) темы, завершающей данный раздел цикла, переносится в средний, затем в верхний регистр, и замирает на ррp.

В моментах активного развития музыкального материала усиливается значение метроритма и даже появляются тактовые черты (сплошные или курсивные). Так оказываются противопоставленными трех- (19-32 тт., 72-82 тт., 85-86 тт., 143-147 тт.) и четырехдольность (34-64 тт., 85-104 тт.), частая смена которых в тактах с 108-го по 132-й входит в кульминационную зону, становясь дополнительным средством контраста. 
II часть Сонаты - скерцо - открывает quasi-токкатная тема (Allegro), ритм которой за счет множественных пауз постоянно нарушается, что, в сочетании с тихой динамикой $(p)$, создает образный модус беспокойства, неуверенности, суеты. Нервный импульс сообщают интонационному развитию вплетающиеся в него многократные повторы одного и того же звука (ля второй октавы, си малой октавы, $\phi a$ третьей октавы). Форшлаги (как и повторы отдельных звуков, они впервые встречаются в третьем мотетном звене I части) служат дополнительным дестабилизатором и так ненормированного метроритмически звучания.

Вторая тема скерцо (Poco meno mosso (Allegro moderato) - задорная, удалая плясовая, четко проартикулированная $(f$, marcato, ben ritmato), соответственно гораздо более решительная по характеру, чем первая тема.

Третий рефрен следует сразу за вторым и близок по типу тематизма первой теме; представляет собой своего рода «взвесь» ее стаккатирующих, непрерывно паузирующих интонационных компонентов.

В процессе развития второй темы подключаются форшлаговые «курлыкания» из I части, благодаря которым этот рефрен, помещенный в верхний регистр, приобретает «звоновую» (колокольчиковую) окраску. Как мы увидим в дальнейшем, «звоновость» является важнейшей сонорной «краской» II части.

В 238-240 тактах вторая тема скерцо контрапунктирует с песенно-лирической темой из третьего звена I части, приобретающей за счет многократных кадансового типа опеваний-окончаний характер колыбельной.

Далее звучит четвертая тема главной партии I части, сопровождаемая «звоновыми» верхнерегистровыми триольными фигурациями (в конце данного фразового построения она, «поддаваясь» общему движению, ритмически сокращена до восьмых длительностей и прерывается паузами, а также перемещается в басы, соответственно звучит «механистически» и угрожающе).

Затем проходит былинная тема I части в ее новом «романтизированном» амплуа (яркая динамика, гомофонно-гармоническая фактура, октавные дубли самой темы и баса, а также фигурации по звукам аккордов).

Следующий эпизод представляет один из этапов в развитии «отношений» токкатно-агрессивного, наступательного и лирического образов (у последнего много интонационных «эмблем», народно- 
песенных, преимущественно, попевочных). Продолжающие свое «самодвижение» фигурации исполняются non legato, для большего контраста с соединяющейся с ними по горизонтали второй темой главной партии I части, которая проходит сначала в одноголосном изложении, затем в аккордовом (очередной «островок» ладовости).

Последующий фрагмент по тематизму и фактуре идентичен предыдущему эпизоду, однако контрастная динамика $(f$ в противоположность предшествующим $p p$, а до того - $p$ ) и штрихи (marcato, сменившее cantabile), авторская ремарка con fиосо позволяют говорить о новом этапе - уровне развития музыкального материала.

Такое же «жесткое», «сухое», «глухое» за счет неожиданной смены динамического оттенка на $p$ звучание имеет и столь же внезапно «переметнувшаяся» в другой лагерь, изменившая своим семантическим ориентирам, изначально лирическая, вторая тема третьего мотетного звена I части (такты 296-320). Далее «смена масок» для этой темы продолжается: начиная с 320-321-го тактов и вплоть до 356-го она воцаряется в верхнем регистре, становится ударно-звоновой, приобретает аккордовое изложение, окрашивается форшлагами и глиссандо и, что самое главное, обнаруживает отдаленную ритмоинтонационную близость «теме-раскачке» Рапсодии в блюзовых тонах Д. Гершвина. Чередующиеся с искряшимся колокольным звучанием, «яростно» противостоят ему «унифицированные» пассажи, изложенные шестнадцатыми длительностями. Мелькает единожды в этом звуковом потоке, напоминающий о небезоблачности «серебряного» звона, тихий (на $p)$, но «угрожающий» вариант былинной темы (326329 тт.).

Такты с 356-го по 377-й завершают обыгрывание «звоновых» элементов, с 378-го по 418-й - знаменуют временную «победу» токкатности, которая в дальнейшем усиливается подключением интонаций, аллюзивных к основной теме (первому рефрену) II части.

Гневное звучание основного рефрена II части (одноголосное изложение, как при первом проведении) сменяет полифонический эпизод: пуантилистический «точечный» эффект звучания здесь достигается большим расстоянием между звуками, их «стаккатной» подачей (в дополнение к этому Слонимский ставит специальную ремарку martellato; также замедляется темп). В эту музыкальную ткань удачно вписывается (а, возможно, и наоборот, продуцирует ее) основная тема I части, которая образует нижний голос трехголосия, изложенного в виде «партитуры» (на трех нотных станах). 
469-й такт отмечен ярким динамически и артикуляционно знаменующим возвращение исходного темпа «смелым» появлением четвертой темы главной партии I части, контрапуктически сочетающейся с продолжающими свой «бег» «злыми» фигурационными элементами.

Эпизод Allegro ben ritmato - последняя схватка противоборствующих сил. Победно - в аккордовом сопровождении - звучит первый рефрен. Ранее имеющая «серебряную» окраску, звоновость обретает иной, разрушительно-набатный смысл. Выползают изо всех щелей, из темных углов бесы, ширится армия злых сил. То и дело появляется, подбавляя масло в полыхающее пламя пожарища, второй, тревожный элемент (с триолью шестнадцатыми) первой побочной партии из I части, приобретающий здесь грозный лик темы Рока. Вновь, на фоне безостановочного звоново-аккордового движения шестнадцатыми в верхнем регистре, проводится в басу основная тема Сонаты.

Торжество зла символизирует появление в басу, дважды дублированное в октаву, на $f f$, первой темы I части сочинения. К ней примыкает победное звучание темы Рока.

Кода (раздел Tranquillo, l'istesso tempo) выполняет катартическую функцию. Медленно, неспешно разворачивается перед нами мистическая картина инобытия, брезжащего потусторонненого света, в котором только и оказывается возможным безмятежное счастье и покой. Колорит просветляется. На фоне зыбких «звоновых» фигураций на $p p p$, придающих на этот раз звучанию некоторую статику, вместе с тем, умиротворенность, проходят темы-символы добра из I части: первая побочная (с 558-го т.), вторая главная партия (с 538-го т.), вторая фаза третьего звена (с 606-го т.). В последних тактах на фоне истаивающего фигурационного движения отчетливо слышится звучание «большого колокола». Картину преображенного Китежа заволакивает дымка...

Замечательно, аналитически точно - с точки зрения лада - как «освобождение трихордовой диатоники от внутризонных вариантов» (то есть конфликтных противопоставлений двух тоник Сонаты $-c u$ и до) и установление ладового центра до описывает коду И. Рогалев. Однако такое просветление, установление ладовой «гармонии», к сожалению, неверно считать, как предполагает исследователь, реальной победой добра [2, с. 437]. Конфликт исчерпан смертью, но получает посттрагическое разрешение. 
Игровая логика Сонаты диктует в скерцо большую дробность мозаичной комбинаторики, чем в I части, поскольку одни и те же темы могут проявлять как «положительные», так и «отрицательные» свои качества. Разнохарактерные мотивы в процессе развития обнаруживают сходство.

При этом два полярных полюса реализованы в музыкальном языке и драматургии всего сочинения достаточно своеобразно; в рамках всего цикла - как противопоставление тем принципиально ладотонально неопределяемых, не народно-песенного происхождения мотивам тоникально ясным, с характерной для фольклора ладовой окраской. И. Рогалев, напомним, указывает на значительность для драматургии Сонаты ладового сопряжения (более подробно об этом см. [2]).

Антитеза II части углубляет и проясняет основной конфликт посредством нового темпового «формата», ускоряющего ход времени и дающего возможность посостязаться двум противоборствующим силам. Ритмически неопределенный, «рваный», но набирающий обороты Allegro инструментальный и «речевой» (говор, шепот, гул толпы и т. п.) тип тематизма становится воплощением механистичности, унифицированности, бездушности и бездуховности. Ему противостоят более спокойные, но вовлеченные «помимо воли» в водоворот событий, отражающие иной ход времени, иное, позитивно-созидательное представление о жизни, осмысленность в каждом действии и слове, песенно-лирические (стилизуемые под народные, попевочные, без широкой распевности, за исключением, разве что, третьей темы главной партии I части) мелодии.

(Таким образом, мы не согласны ни с Л. Баренбоймом, который считает, что мелодика Сонаты целиком базируется исключительно на вокально-речевых интонациях [1, с. 367-368], ни с О. Щербатовой, разделяющее звучание в данном произведении на, с одной стороны, вокально-хоровое, с другой - инструментальное [5]).

II часть Сонаты, на наш взгляд, совмещает композиционные функции (В. Бобровский) собственно скерцо и быстрого финала сонатно-симфонического цикла.

Композитором предусмотрены оговоренные в тексте Сонаты в словесных ремарках четыре незначительные для драматургии и общего музыкального развития купюры, которые совсем ненадолго сокращают время звучания сочинения. Это 9 тактов в I части (начиная с 99-го), а также 7 (начиная с 282-го), 2 (362-363) и 4 (507-510) во II части. 
Из статьи Л. Баренбойма узнаем: советская цензура указала как на недостаток (композиционную провинность Слонимского) на наличие в музыке Сонаты некоторых «длиннот» [1]. По-видимому, введение композитором купюр являются уступкой (исходя из их объема весьма незначительной) требованиям исполнителей.

Один из интерпретаторов Сонаты, пианист Анатолий Угорский (запись 1970 г.), неоднократно пользуется купюрами, не только авторскими, но и собственными, что нарушает целостность сочинения, особенно если помнить о тщательно продуманной композитором многозвеньевости интонационно-тематического развития.

В другой, современной записи Ивана Александрова (2012 г., СанктПетербург, МЗФ) купюр нет. Но, в свою очередь, агогические отклонения, применяемые эти пианистом, придают звучанию Сонаты несвойственный ему романтизированный характер. «Прокофьевская» исполнительская манера Угорского оказывается здесь более уместной.

В I части Сонаты нет обозначения размера, а, следовательно, «свободный» метроритм максимально повышает значение фразировки.

С другой стороны, Слонимский широко пользуется приемами «замыкания», что значительно облегчает моделирование фразировочного «сценария».

По отношению к I части такие приемы встречаются повсеместно. Во-первых, в ее финальных тактах наступает интонационная и ладовая реминисценция. Во-вторых, все «мотетные» звенья или основные тематические построения и их дальнейшие повторы обнаруживают определенную замкнутость. В-третьих, дополнительными факторами членения являются сплошные и пунктирные тактовые черты. Прием использования «quasi-черт» помогает во фразировочном анализе, поскольку обозначение пунктиром часто соответствует внутреннему наполнению фразировочной волны.

Особого внимания при работе над фразировкой - «выпевания» или, напротив, «токкатности», - требуют фрагменты, в которых фортепиано трактуется как одноголосный инструмент. С другой стороны, некоторые полифонические пласты, образуемые посредством одновременного проведения в разных голосах тем и мотивов, нуждаются в соответственном «фугированном» звучании (если к тому располагает тематизм) или создании пространственных эффектов, приближающихся к антифонному звучанию. Особой «жесткой», «Хлесткой», одновременно, «размашистой» манеры исполнения требуют «колокольные перезвоны». 
Исходя из всего вышеизложенного, можно сделать вывод, что в Фортепианной сонате Слонимский экспериментирует с формой, которая понимается исследователями по-разному - от сонатного аллегро «высшего порядка» до своеобразно трактованного трехчастного цикла. Мы полагаем, что в данном сочинении из-за «наложения» композиционных функций своеобразно претворились черты четырехчастного сонатно-симфонического цикла. Так, I часть совмещает функции сонатного аллегро и медленной части, а II часть, скерцо функции собственно скерцо и быстрого финала.

Мозаичность делает скерцо-финал Сонаты чрезвычайно напряженным. Частая смена интонационно-тематических образований и их контрапунктические соединения, семантическое переиначивание мотивов, вплоть до кардинальных, прямо противоположных вариантов-антиподов, преврашают эту часть в смысловой «концентрат» цикла.

Драматургия, структура, музыкальный язык и особенности исполнения Фортепианной сонаты С. Слонимского ярко индивидуальны и «раскрываются» лишь посредством вхождения в авторский круг образов и музыкально-выразительных средств.

\section{СПИСОК ЛИТЕРАТУРЫ}

1. Баренбойм Л. Соната для фортепиано С. Слонимского / Л. Баренбойм // Вольные мысли. К юбилею С. Слонимского / [ред.-сост. Т. Зайцева, Р. Слонимская]. - СПб. : Композитор-Санкт-Петербург, 2003. - С. 362-368.

2. Рогалев И. Об одном аспекте формообразующего процесса в музыке С. Слонимского / И. Рогалев // Вольные мысли. К юбилею С. Слонимского / [ред.-сост. Т. Зайцева, Р. Слонимская]. - СПб. : Композитор-СанктПетербург, 2003. - С. 426-438.

3. Рыцарева М. Композитор Сергей Слонимский / М. Рыцарева. - Л. : Советский композитор, 1991. - 256 с. : ил.

4. Слонимский С. Соната для фортепиано / С. Слонимский. - СПб. : Композитор-Санкт-Петербург, 2008. - 64 с.

5. Щербатова О. Звуковой образ инструмента в сольных фортепианных произведениях отечественных композиторов 60-80-х годов XX века : автореф. дис. ... канд. искусств. : 17.00 .02 / О. А. Щербатова. - Нижний Новгород, 2012. $-22 \mathrm{c}$.

Сапсович О. Фортепіанна соната С. Слонимського: особливості формоутворення та виконавської інтерпретації. У статті розглядаються формотворчі принципи Фортепіанної сонати С. Слонимського. З'ясовується, що в творі втілилися риси чотирьохчастного симфонічного циклу, де I частина поєднує 
композиційні функції (В. Бобровський) сонатного алегро та повільної частини, а II частина - скерцо і швидкого фіналу. В аналізі виконавської інтерпретації спеціальну увагу приділено проблемам фразування, а також питанням правомірності частково редукованого (з купюрами) виконання.

Ключові слова: драматургія, формоутворення, фразування, композиційні функції, принцип мотетності.

Sapsovich O. Sonata for Piano by S. Slonimsky: features of the forming and the performing interpretation. The article deals with formative principles of Sonata for Piano by S. Slonimsky. The features of a four-part symphony cycle put it in this piece, where The Part I combines composite functions (B. Bobrovskiy) of sonata allegro and a slow part, and The Part II combines a scherzo and a fast finale. In a performing analysis the special attention pays to the problems of phrasing, as well as on the legality of partially reduced (with cuts) performance.

Keywords: dramaturgy, forming, phrasing, composite functions, motet's principle.

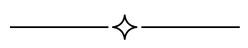

УДК $78.03+78.071 .22$

\section{A. Мурза}

\section{ГАСТРОЛИ В. В. АНДРЕЕВА 1912-1913 ГОДОВ И ИХ РОЛЬ В ФОРМИРОВАНИИ БАЛАЛАЕЧНОГО ИСКУССТВА УКРАИНЫ}

Статья посвящена этапу формирования балалаечного и народно-оркестрового жанра в Украине в их ориентации на дальнейшую академизацию. Подчеркивается значение внимания уже на начальных этапах $\kappa$ различным средствам исполнительской выразительности (прежде всего к работе над звуком) в их комплексном воздействии на слушателя. Приводятся редкие архивные материалы по гастрольным выступлениям В. В. Андреева как солиста-балалаечника и дирижера домрово-балалаечного оркестра.

Ключевые слова: балалайка, домрово-балалаечный оркестр, «Великорусский оркестр», В. В. Андреев, балалаечное искусство Украины.

Усовершенствование В. В. Андреевым народных инструментов в конце XIX века, создание на их основе нового типа оркестра (домрово-балалаечного) и его выход на академическую сцену привели к возникновению самобытного вида искусства. Трудно переоценить вклад в мировую музыкальную культуру страстного пропагандиста 